\title{
CRITERIA-EVALUATION APPARATUS OF BACHELORS' PROFESSIONAL AND LEGAL COMPETENCE DEVELOPMENT
}

(C) 2018

Knyazeva Anna Gennadyevna, senior lecturer

of Theory and History of Social Pedagogy and Social Work Department

Orel State University named after I.S. Turgenev (Orel, Russian Federation)

Abstract. The paper raises a question of assessing professional and legal competence of bachelors majoring in social work at university. Professional and legal competence is a professional property of a graduate in the field of social work, which can effectively solve professional problems in the field of legal regulation of social protection of the population. Attention is paid to the relevance of this professional quality among specialists for modern Russia. The instrument of its evaluation is the criteria-evaluation apparatus, including motivational criterion (indicators: educational, professional motives, interest in law); content-cognitive criterion (indicators: knowledge of the theory of states and law, main branches of Russian law, knowledge of legal acts in the field of regulation of social protection of the population); creative activity criterion (indicators: ability to apply skills and abilities for solving professional and legal problems, sequence of tasks, knowledge of methods of search, analysis and application of normative legal acts in the field of social protection of the population); regulatory and reflexive criteria (indicators: stability in behavior, self-assessment of cognitive activity and sequence of tasks). The paper contains a brief review of research on the development of criteria and indicators for assessing various pedagogical phenomena. The author focuses on the systematic approach as a methodological basis for the analysis of the criteria-evaluation apparatus, which proposes to be considered as an integrative integrity, including the purpose, object, subjects, subject, content and result. Criteriaevaluation apparatus of bachelors' professional and legal competence development can be used in the system of advanced training of specialists in social work.

Keywords: bachelor of social work; professional and legal competence; professional and legal activity; motivational criteria; content-cognitive criteria; creative-activity criteria; regulatory-reflexive criteria; indicators; diagnostic tools; systematic approach; integrative integrity.

\section{ФОРМИРОВАНИЕ ПРОФЕССИОНАЛЬНЫХ КОМПЕТЕНЦИЙ СТУДЕНТОВ НАПРАВЛЕНИЯ ПОДГОТОВКИ «ПЕДАГОГИЧЕСКОЕ ОБРАЗОВАНИЕ» ПРОФИЛЕЙ «НАЧАЛЬНОЕ ОБРАЗОВАНИЕ» И «ИНОСТРАННЫЙ ЯЗЫК»}

(C) 2018

\author{
Кочетова Наталья Геннадьевна, кандидат физико-математических наук, доцент, \\ декан факультета начального образования
}

Стройков Сергей Александрович, кандидат филологических наук, доцент кафедры иностранных языков Самарский государственный социально-педагогический университет (2. Самара, Российская Федераиия)

Аннотащия. Настоящая статья посвящена проблеме формирования профессиональных компетенций студентов направления подготовки 44.03.05 Педагогическое образование профилей «Начальное образование» и «Иностранный язык». На основе анализа нормативных документов, определяющих требования государства и образовательных организаций (работодателей) к подготовке учителя, авторы работы выстраивают соотношение требований к должности учителя, которые содержатся в федеральном государственном образовательном стандарте основного общего образования, в федеральном государственном образовательном стандарте высшего образования и в профессиональном стандарте «Педагог», обобщают опыт формирования профессиональных компетенций бакалавров на факультете начального образования и на примере ПК-4 представляют покомпонентную характеристику компетенции, а также представляют методики покомпонентной диагностики сформированности данной профессиональной компетенции, отмечают целесообразность введения специальных компетенций по профилю «Иностранный язык», на примере СКИЯ-2 представляют покомпонентную характеристику компетенции. В статье также рассмотрены проблемы формирования профессиональных компетенций студентов направления подготовки 44.03.05 Педагогическое образование профилей «Начальное образование» и «Иностранный язык».

Ключевые слова: компетенция; профессиональные компетенции; специальные компетенции; формирование профессиональных компетенций; покомпонентная характеристика; учитель; педагогическое образование; иностранный язык; стандарт; профессиональный стандарт; методика; диагностика.

Изменения, происходящие в системе образования России, предъявляют высокие требования к подготовке учителя. Процесс формирования профессиональных компетенций студентов направления подготовки 44.03.05 Педагогическое образование профилей «Начальное образование» и «Иностранный язык» регламентируется рядом правовых и нормативных документов, определяющих требования государства и образовательных организаций (работодателей): федеральные государственные образовательные стандарты начального общего образования [1], основного общего образования [2] и среднего (полного) общего образования [3]; единый квалификационный справочник должностей руководителей, специалистов и 
Кочетова Н.Г., Стройков С.А.

служащих, раздел «Квалификационные характеристики должностей работников образования» [4]; профессиональный стандарт «Педагог (педагогическая деятельность в сфере дошкольного, начального общего, основного общего, среднего общего образования) (воспитатель, учитель)» [5]; Федеральный государственный образовательный стандарт высшего образования, уровень высшего образования бакалавриат, направление подготовки 44.03.05 Педагогическое образование (с двумя профилями подготовки) [6].

Федеральные государственные образовательные стандарты общего образования требуют от учителя соответствующего уровня квалификации, включающего «компетентность в предметной области знаний и методах обучения, общую культуру, самоорганизованность, эмоциональную устойчивость», а также владения профессиональными компетенциями для реализации требований стандарта и успешного достижения учащимися планируемых результатов освоения образовательной программы. Поэтому понятие «профессиональные компетенции учителя» будем рассматривать с позиции системного подхода и определим, как актуализированную систему ценностей, умений и навыков в психолого-педагогической и предметно-методической областях знаний, способную воплощаться в педагогической деятельности учителя.

Для учителя начальных классов спектр предметных областей знаний достаточно широк (естественно-математические, филологические, художественно-эстетические). В этой логике выстроен учебный план основной образовательной программы: выделены предметные области и объединены в них дисциплины, изучение которых готовит студентов к обучению по предмету в школе.

Требования к кадровым условиям реализации основной образовательной программы общего образования ограничиваются двумя положениями: уровень квалификации педагогических работников образовательного учреждения; непрерывность профессионального развития педагогических работников образовательного учреждения. Уровень квалификации работников, реализующих программу образования, должен соответствовать квалификационным характеристикам по соответствующей должности. Непрерывность профессионального развития работников должна обеспечиваться освоением дополнительных профессиональных образовательных программ в объеме не менее 72 часов, не реже чем каждые пять лет. Квалификационная характеристика должности «учитель» представлена в едином квалификационном справочнике (раздел для работников образования), она содержит должностные обязанности (по обучению и воспитанию обучающихся в рамках ФГОС); знания, которыми должен владеть учитель; требования к квалификации, указывающие на уровень образования.

Среди должностных обязанностей учителя следующие: (1) осуществляет обучение и воспитание обучающихся с учетом их психолого-физиологических особенностей и специфики преподаваемого предмета в рамках федеральных государственных образовательных стандартов; (2) обоснованно выбирает программы и учебно-методическое обеспечение, проводит учебные занятия, опираясь на дости- жения в области педагогической и психологической наук; (3) планирует и осуществляет учебный процесс в соответствии с образовательной программой образовательного учреждения, разрабатывает рабочую программу по предмету; (4) оценивает эффективность и результаты обучения обучающихся по предмету, осуществляет контрольно-оценочную деятельность в образовательном процессе; (5) обеспечивает охрану жизни и здоровья обучающихся во время образовательного процесса. Осуществляет связь с родителями (лицами, их заменяющими).

Профессиональный стандарт «Педагог» применяется работодателями при формировании кадровой политики. В описании трудовых функций, входящих в ПС (общепедагогическая функция. обучение; воспитательная деятельность; развивающая деятельность) рекомендовано ориентироваться на трудовые действия, необходимые в профессиональной деятельности педагога, необходимые умения и знания.

Результаты высшего образования сформулированы в виде набора компетенций, то есть комплексов индивидуальных характеристик, необходимых и достаточных для эффективного и гарантированного осуществления профессиональной деятельности в заданных условиях и на заданном уровне качества. В ФГОС ВО по направлению «Педагогическое образование» выделены две группы профессиональных компетенций: шесть ОПК и четырнадцать ПК по видам профессиональной деятельности (педагогической - семь, проектной - три, научно-исследовательской - две, культурно-просветительской - две).

Таким образом, требования к должности учителя в рассмотренных документах представлены разными категориями (уровнем квалификации, должностными обязанностями, знаниями, трудовыми функциями и действиями, умениями, профессиональные компетенции).

Попытаемся установить их соотношение в таблице 1.

Таблица 1 - Соотношение ФГОС ОО (квалификационный справочник), ФГОС ВО и ПС «Педагог»

\begin{tabular}{|l|c|c|}
\hline $\begin{array}{c}\text { ФГОС ОО } \\
\text { (квалификацион- } \\
\text { ный справочник) }\end{array}$ & ФГОС ВО & ПС «Педагог» \\
\hline $\begin{array}{l}\text { должностные обя- } \\
\text { занности }\end{array}$ & $\begin{array}{c}\text { виды дея- } \\
\text { тельности }\end{array}$ & $\begin{array}{c}\text { трудовые функ- } \\
\text { ции }\end{array}$ \\
\hline $\begin{array}{l}\text { должностные обя- } \\
\text { занности }\end{array}$ & $\begin{array}{c}\text { професси- } \\
\text { ональные } \\
\text { задачи }\end{array}$ & $\begin{array}{c}\text { трудовые дей- } \\
\text { ствия }\end{array}$ \\
\hline $\begin{array}{l}\text { должностные обя- } \\
\text { занности, знания } \\
\text { компетен- } \\
\text { ции }\end{array}$ & $\begin{array}{c}\text { необходимые } \\
\text { уения и необхо- } \\
\text { димые знания }\end{array}$ \\
\hline
\end{tabular}

Перечень профессиональных компетенций, представленных в стандарте ВО по педагогическому направлению, является весьма обобщенным и универсальным для педагогов всех учебных предметов и не учитывает специфики как профессиональной (профильной) подготовки учителя, так и особенностей его педагогической деятельности. Возникает необходимость конкретизации профессиональных компетенций учителя с учетом основных профессиональных задач, стоящих перед учителем, согласно 
федеральным государственным образовательным стандартам и особенностям его профильной подготовки. Она выражается в образовательных результатах проверяемой компетенции.

Рассмотрим сопоставление требований к учителю начальных классов на примере профессиональной компетенции в области педагогической деятельности ПК-4 (способность использовать возможности образовательной среды для достижения личностных, метапредметных и предметных результатов обучения и обеспечения качества учебно-воспитательного процесса средствами преподаваемых учебных предметов). Ее покомпонентная характеристика, на наш взгляд, может быть представлена следующим образом (табл. 2):

Таблица 2 - Покомпонентная характеристика ПК-4

\begin{tabular}{|c|c|}
\hline $\begin{array}{l}\text { Компонен- } \\
\text { ты компе- } \\
\text { тенции }\end{array}$ & $\begin{array}{c}\text { Содержание } \\
\text { компонентов компетенции }\end{array}$ \\
\hline $\begin{array}{l}\text { Студент } \\
\text { знает }\end{array}$ & $\begin{array}{l}\text { - роль и функции умений в познава- } \\
\text { тельной деятельности человека; } \\
\text { - операционный состав УУд; } \\
\text { - отдельные положения психологии и } \\
\text { дидактики об особенностях формиро- } \\
\text { вания УУд у детей младшего школь- } \\
\text { ного возраста; } \\
\text { - структуру и компоненты учебной } \\
\text { деятельности младших школьников; } \\
\text { - методы и приемы формирования } \\
\text { познавательной деятельности детей; } \\
\text { - психологические закономерности } \\
\text { процесса овладения умственными } \\
\text { действиями. }\end{array}$ \\
\hline $\begin{array}{l}\text { Студент } \\
\text { умеет }\end{array}$ & $\begin{array}{l}\text { - распознавать проблему, в том числе } \\
\text { и по формированию умений, и видеть } \\
\text { набор вариантов ее решения; } \\
\text { - соотносить процесс обучения } \\
\text { младших школьников с психологиче- } \\
\text { скими закономерностями по форми- } \\
\text { рованию умений; } \\
\text { - формировать у детей метапредмет- } \\
\text { ные умения в единстве с предметны- } \\
\text { ми умениями. }\end{array}$ \\
\hline $\begin{array}{l}\text { Студент } \\
\text { владеет }\end{array}$ & $\begin{array}{l}\text { - приемами формирования у детей } \\
\text { метапредметных умений в единстве с } \\
\text { предметными умениями; } \\
\text { - способами организации исследова- } \\
\text { тельской деятельности детей по фор- } \\
\text { мированию таких умений и управле- } \\
\text { ния этой деятельностью. }\end{array}$ \\
\hline $\begin{array}{l}\text { Психоло- } \\
\text { гические } \\
\text { установки }\end{array}$ & $\begin{array}{l}\text { Имеет склонность к педагогической } \\
\text { деятельности. Понимает свою роль } \\
\text { как педагога в образовательном про- } \\
\text { цессе. }\end{array}$ \\
\hline $\begin{array}{l}\text { Личност- } \\
\text { ные каче- } \\
\text { ства }\end{array}$ & $\begin{array}{l}\text { Эмпатия. Способность к рефлексии. } \\
\text { Склонность к авторитарно-демокра- } \\
\text { тическому стилю педагогического } \\
\text { общения. Обладает высоким уровнем } \\
\text { коммуникативных и организаторских } \\
\text { склонностей. }\end{array}$ \\
\hline
\end{tabular}

На итоговом государственном экзамене, проверяя сформированность этой компетенции по представленной технологической карте урока на заданную тему, оценке подлежат следующие образовательные результаты: анализирует профессиональную ситуацию (в комментарии приводятся результаты анализа: какими способами действий должны владеть обучающиеся к моменту урока); формулирует методические задачи на основе анализа профессиональной ситуации (формулирует цели и условия, в которых эта цель достигается); комбинирует методы для рационального решения методической задачи (в комментарии указываются эти методы); в уроке выделяет этапы в соответствии с этапами учебной деятельности; использует приемы преобразования тренировочных заданий в поисковые.

В ПС «Педагог» для ПК-4 рассматривается в качестве обобщенной трудовая функция по реализации программ начального общего образования, трудовые действия, а также необходимые умения: ставить различные виды учебных задач и организовывать их решение в соответствии с уровнем познавательного и личностного развития детей младшего школьного возраста, сохраняя при этом баланс предметной и метапредметной составляющей их содержания.

Формируют рассматриваемую компетенцию следующие дисциплины учебного плана базовой части (Информационно-коммуникационные технологии в образовании; Методика обучения математике, Методика обучения иностранному языку), вариативной части (Технологии языкового литературного образования; Методика обучения русскому языку и литературному чтению; Оценка достижений обучающихся в математическом образовании; Информатика и информационно-коммуникационные технологии в начальной школе), дисциплины и курсы по выбору (Технологии анализа художественного текста; Технологии формирования УУД в обучении математике; Полихудожественное воспитание младшего школьника), а также педагогическая практика.

Результаты ряда диссертационных исследований преподавателей факультета начального образования и СГСПУ (Л.В. Лысогоровой [7], Н.И. Улендеевой [8], И.А. Липенской [9], Т.В. Федоровой [10]) позволили выделить педагогические условия успешного формирования профессиональных компетенций бакалавров начального образования, в том числе и ПК4: организационно-педагогические: практико-ориентированное обучение; осуществление мониторинга формирования профессиональных компетенций; возможность студентам строить индивидуально-образовательную траекторию; осуществление междисциплинарной интеграции; дидактические: практическая направленность педагогических технологий; использование практико-ориентированных заданий на практических занятиях и лабораторных работах; создание студентами в рамках самостоятельной работы реальных проектов; психолого-педагогические: «субъектсубъектные» отношения между преподавателем и студентами; целенаправленное формирование положительного отношения к будущей профессии, понимания необходимости непрерывного образования и т.п.

Содержательной основой для формирования профессиональных компетенций бакалавра являются 
Кочетова Н.Г., Стройков С.А.

также разработанные в процессе исследования и внедренные в образовательный процесс специальные учебные курсы: Н.И. Улендеева - «Основы методического мастерства», Л.В. Лысогорова - «Технологии развития математических способностей младших школьников», И.А. Липенская - «Реализация требований ФГОС НОО в образовательном процессе», Т.В. Федорова - «Технологии развития творческих способностей», «Прогнозирование как педагогическое явление».

Кроме того, преподаватели постоянно совершенствуют содержание и формы организации обучения студентов. Сохраняют свою актуальность лекционные, семинарские, практические и лабораторные занятия. Мы благодарны возможности включения в преподавание методических дисциплин лабораторных занятий. Их проведение мы осуществляем непосредственно в школах, что способствует приобретению опыта квазипрофессиональной деятельности. Практическая направленность используемых педагогических технологий, кейсов, портфолио, включение проектных и практико-ориентированных заданий, в силу их надпредметного характера, способствуют интеграции студентами всех структурных компонентов компетенций.

Организационной основой для формирования профессиональных компетенций служат разработанные тренинги-симуляторы профессиональной деятельности, направленные на организацию профессиональной и квазипрофессиональной деятельности студентов. Они способствуют приобретению студентами профессионального опыта, формированию личностных качеств и психологических установок. Но это лишь первые шаги, направленные на формирование этих элементов компетенций. В большинстве случаев при обучении формируется когнитивнодеятельностный компонент компетенций, то есть знания и умения. Да, собственно, он и отслеживается в образовательных результатах. Поэтому в этом направлении еще предстоит немалая работа.

В диссертационном исследовании Т.В. Федоровой представлены методики покомпонентной диагностики сформированности профессиональной компетенции ПК-4 [10].

Таблица 3 - Методики покомпонентной диагностики сформированности ПК-4

\begin{tabular}{|c|c|}
\hline $\begin{array}{c}\text { Компонент } \\
\text { компетенции }\end{array}$ & Методика диагностики \\
\hline $\begin{array}{l}\text { Теоретические } \\
\text { знания }\end{array}$ & Тест \\
\hline $\begin{array}{l}\text { Деятельност- } \\
\text { ный компо- } \\
\text { нент (владе- } \\
\text { ние умениями, } \\
\text { навыками) }\end{array}$ & $\begin{array}{l}\text { Экспертная оценка (анализ прове- } \\
\text { денного урока, производственная } \\
\text { практика) }\end{array}$ \\
\hline $\begin{array}{l}\text { Психологиче- } \\
\text { ские установ- } \\
\text { ки (мотивы, } \\
\text { склонности) }\end{array}$ & $\begin{array}{l}\text { Дифференциально-диагностичес- } \\
\text { кий опросник (ДДО) Е.А. Климова } \\
\text { (адаптированный). } \\
\text { Методика КОС В.В. Синявского и } \\
\text { Б.А. Федоришина, Методика изу- } \\
\text { чения мотивации к достижению } \\
\text { успеха Т. Элерса }\end{array}$ \\
\hline $\begin{array}{l}\text { Личностные } \\
\text { качества } \\
\text { (эмпатия) }\end{array}$ & Методика A. Merabian и N. Epstein \\
\hline
\end{tabular}

Самарский научный вестник. 2018. Т. 7, № 1 (22)
Формирование профессиональных компетенций невозможно без привлечения будущих педагогов к практической деятельности. В процессе педагогической практики применяются и осмысливаются теоретические знания, интенсифицируется развитие педагогического мышления, творческих способностей студентов. В то же время педагогическая практика этап личностного формирования будущего учителя, развития его общей и профессиональной культуры. Личностная самореализация выступает условием динамичного и постоянного совершенствования деятельности будущего учителя. Непосредственно на педагогической практике мы используем возможности супервизии. Мы вносим изменения в программу и формы организации учебной практики: делаем ее рассредоточенной (один день в неделю) с конкретными заданиями на каждый день и сопровождением не только педагога, но и психолога. Традиционные встречи преподавателей и студентов факультета с работодателями способствует выстраиванию процесса формирования профессиональных компетенций студентов: вносятся изменения в учебные планы, формы организации занятий и практик, выполнение ВКР по заявкам школ. Тематика ВКР напрямую связана с формированием ПК-4: формирование определенной группы УУД (познавательных, регулятивных, коммуникативных) младших школьников при обучении различным предметам, проектирование образовательной среды для формирования метапредметных результатов и прочее.

Кроме того, как уже отмечалось выше, профессиональные компетенции федерального государственного образовательного стандарта высшего образования по направлению подготовки 44.03.05 Педагогическое образование (с двумя профилями) универсальные для педагогов всех учебных предметов и не учитыввают специфику профессиональной или профильной подготовки учителя иностранного языка, при этом образовательная организация вправе дополнить набор компетенций выпускников с учетом направленности программы бакалавриата на конкретные области знания и вид деятельности.

По этим причинам формирование профессиональных компетенций педагогов, обучающихся по профилям «Начальное образование» и «Иностранный язык», включает формирование специальных компетенций, под которыми мы понимаем вид профессиональных компетенций, характеризующих функциональную специфику выбранной профессиональной деятельности [9]. Необходимость формирования специальных компетенций по профилю «Иностранный язык» продиктована также тем, что при поступлении в вуз не учитывается уровень владения иностранным языком, поскольку ЕГЭ по иностранному языку не является обязательным. Специальные компетенции по профилю «Иностранный язык» заимствованы из ФГОС ВО направление подготовки 45.03 .02 Лингвистика [11] и сформулированы следующим образом: СКИЯ-1: обладает навыками социокультурной и межкультурной коммуникации, обеспечивающими адекватность социальных и профессиональных контактов; СКИЯ-2: владеет системой лингвистических знаний, включающей в себя знание основных фонетических, лексических, грамматических, словообразовательных явлений и зако- 
номерностей функционирования языка, его функциональных разновидностей; СКИЯ-3: знает основные способы достижения эквивалентности в переводе и умеет применять основные приемы перевода.

Рассмотрим на примере СКИЯ-2 содержание компонентов этой специальной компетенции: студент знает: основные фонетические, лексические, грамматические, словообразовательные и стилистические явления и закономерности функционирования изучаемого иностранного языка, его функциональные разновидности; студент умеет: находить в тексте и объяснять закономерности функционирования основных фонетических, лексических, грамматических, словообразовательных и стилистических явлений изучаемого языка; студент владеет: практическим опытом изложения основного содержания аутентичного художественного текста в реферативной форме на английском языке, высказывания своего собственного мнения по тексту и анализа лексических выразительных средств и стилистических приемов.

Рассматриваемые нами специальные компетенции являются предметным компонентом профессиональной компетентности будущего учителя иностранного языка и формируются характеризующимися междисциплинарной интеграцией обязательными дисциплинами и дисциплинами по выбору вариативной части учебного плана: СКИЯ-1 формируют следующие дисциплины по выбору - Информационные технологии в преподавании иностранного языка и Организация презентаций на иностранном языке. СКИЯ-2 формируют обязательные дисциплины вариативной части - Практика устной и письменной речи, Практическая фонетика, Введение в языкознание, Лексикология, Стилистика, Теоретическая грамматика, Теоретическая фонетика, а также дисциплины по выбору - Основы профессиональноориентированного перевода, Особенности языка и стиля англоязычной прессы, Филологический анализ текста, Интерпретация текстов разных жанров. СКИЯ-3 формируют следующие дисциплины по выбору - Основы профессионально-ориентированного перевода и Особенности языка и стиля англоязычной прессы.

Учебно-методическим обеспечением данных дисциплин являются учебники, рекомендованные учебно-методическим объединением по образованию в области лингвистики Министерства образования и науки Российской Федерации; учебники, рекомендованные Министерством образования и науки Российской Федерации; аутентичные пособия таких известных издательств, как Кембриджского и Оксфордского университетов, Пирсон Лонгман и Макмиллан, а также диссертационные исследования и разработанные профессорско-преподавательским составом кафедры иностранных языков СГСПУ (А.В. Грицковой, А.Ю. Лапшиной, Т.Г. Николаевой, С.А. Стройковым, Т.А. Сухомлиной и М.А. Торгашовой) учебные пособия.

Профессиональные компетенции формируются дисциплинами кафедры иностранных языков совместно с дисциплинами факультета начального образования, в том числе и в ходе педагогической практики, которые студенты проходят и по профилю «Иностранный язык». Вместе с тем мы вынуждены констатировать, что сокращение сроков проведения педагогической практики при подготовке по двум профилям (4 недели) негативно сказывается на процессе формирования профессиональных компетенций педагога. Еще одна проблема, которая нас беспокоит в этом процессе, это обеспеченность действующими школьными учебниками для начальных классов, а точнее - их отсутствие. Проблемой также является отсутствие возможности использования учебно-методических комплексов как отечественных, так и зарубежных для общеобразовательной школы по иностранному языку, которые, как правило, содержат учебник, рабочую тетрадь, книгу для учителя, аудио- и видеоматериалы на дисках и контрольно-измерительные материалы. Зарубежные комплекты таких УМК достаточно дорогие, тем не менее в рамках курса Методика преподавания иностранного языка использование таких УМК было бы очень полезным.

\section{Список литературы:}

1. Федеральный государственный образовательный стандарт начального общего образования (приказ Министерства образования и науки РФ от 6 октября 2009 г. № 373, в ред. Приказов Минобрнауки РФ от 26.11.2010 № 1241, от 22.09.2011 № 2357, от 18.12.2012 № 1060 , от 29.12.2014 № 1643 , от 18.05.2015 № 507, от 31.12.2015 № 1576).

2. Федеральный государственный образовательный стандарт основного общего образования (приказ Министерства образования и науки РФ от 17 декабря 2010 г. № 1897, в ред. Приказов Минобрнауки РФ от 29.12.2014 № 1644, от 31.12.2015 № 1577).

3. Федеральный государственный образовательный стандарт среднего (полного) общего образования (приказ Министерства образования и науки РФ от 17 мая 2012 г. № 413, в ред. Приказов Минобрнауки РФ от 29.12.2014 № 1645, от 31.12.2015 № 1578, от 29.06.2017 № 613).

4. Единый квалификационный справочник должностей руководителей, специалистов и служащих, раздел «Квалификационные характеристики должностей работников образования» (приказ Министерства здравоохранения и социального развития РФ от 26 августа 2010 г. № 761н, в ред. Приказа Минздравсоцразвития РФ от 31.05.2011 № 448н).

5. Профессиональный стандарт «Педагог (педагогическая деятельность в сфере дошкольного, начального общего, основного общего, среднего общего образования) (воспитатель, учитель)» (приказ Министерства образования и науки РФ от 18 октября 2013 г. № 544н, в ред. Приказа Минтруда РФ от 05.08.2016 № 422н).

6. Федеральный государственный образовательный стандарт высшего образования, уровень высшего образования бакалавриат, направление подготовки 44.03.05 Педагогическое образование (с двумя профилями подготовки) (приказ Министерства образования и науки РФ от 9 февраля 2016 г. № 91).

7. Лысогорова Л.В. Технология подготовки будущего учителя к развитию математических способностей младших школьников: автореф. дис. ... канд. пед. наук: 13.00.08. Самара, 2007. 23 с.

8. Улендеева Н.И. Технология формирования интегративных дидактических умений в профессиональной подготовке будущего учителя начальных 
классов: автореф. дис. ... канд. пед. наук: 13.00.08. Самара, 2010. 22 с.

9. Липенская И.А. Формирование специальных компетенций бакалавра: профиль «Начальное образование»: автореф. дис. ... канд. пед. наук: 13.00.08. Самара, 2014. 25 с.

10. Федорова Т.В. Организационно-функциональная модель подготовки педагога к формированию у младших школьников умения прогнозировать: дис ... канд. пед. наук: 13.00.08. Самара, 2017. 270 с.

11. Федеральный государственный образовательный стандарт высшего образования, уровень высшего образования бакалавриат, направление подготовки 45.03.02 Лингвистика (приказ Министерства образования и науки РФ от 7 августа 2014 г. № 940).

\title{
DEVELOPMENT OF PROFESSIONAL COMPETENCIES OF STUDENTS, MAJORING IN «PEDAGOGICAL EDUCATION» («PRIMARY EDUCATION» AND «FOREIGN LANGUAGE»)
} (C) 2018

Kochetova Natalya Gennadyevna, candidate of physics and mathematical sciences, associate professor, head of Primary Education Department

Stroykov Sergey Aleksandrovich, candidate of philological sciences, associate professor of Foreign Languages Department

Samara State University of Social Sciences and Education (Samara, Russian Federation)

Abstract. The following paper considers development of professional competencies of students, majoring in «Pedagogical education» («Primary education» and «Foreign Language»). The authors analyze legal regulations to teacher training and correlate demands to the teacher that are enumerated in federal state educational standard of general secondary education, in federal state educational standard of higher education and in the professional standard «Teacher». The paper also contains Primary Education Department experience of professional competencies development. Based on the example of Professional Competence 4 development the authors introduce its components characteristics as well as diagnostic methods of this professional competence development. The authors note that it is necessary to develop special professional competencies of students, majoring in «Pedagogical education» («Primary education» and «Foreign Language»). Based on the example of Special Professional Competence (Foreign Language) 2 the authors introduce its components characteristics. The paper also contains problems that Primary Education Department and Foreign Languages Department face while developing professional competencies of students, majoring in «Pedagogical education» («Primary education» and «Foreign Language»).

Keywords: competence; professional competencies; special competencies; professional competencies development; components characteristics; teacher; pedagogical education; foreign language; standard; professional standard; methods; diagnostics.

УДК 372.857

Статья поступила в редакцию 07.01.2018

\section{СОСТОЯНИЕ ПРОБЛЕМЫ РАЗВИТИЯ УЧАЩИХСЯ В ТЕОРИИ И ПРАКТИКЕ ОТЕЧЕСТВЕННОЙ ШКОЛЫ ДО 1917 ГОДА (НА ПРИМЕРЕ ЕСТЕСТВОЗНАНИЯ)}

(C) 2018

\author{
Ламехова Елена Анатольевна, кандидат педагогических наук, \\ доцент кафедры общей биологии и физиологии \\ Южно-Уральский государственный гуманитарно-педагогический университет \\ (2. Челябинск, Российская Федеращия)
}

\begin{abstract}
Аннотащия. В статье рассматривается проблема взаимосвязи обучения, воспитания и развития учащихся в процессе изучения естественных наук, всегда интересовавшая педагогов и методистов. Особенно актуальна эта проблема сейчас в связи с дальнейшим внедрением ФГОС среднего общего образования, нацеливающего школу на создание условий для развития и самореализации обучающихся. Более подробно в статье рассматривается трактовка взаимосвязи обучения, воспитания и развития в образовательном процессе в отечественной педагогике в период до 1917 года. Отмечается, что педагоги России и Европы к идее взаимосвязи воспитания и развития в ходе обучения детей пришли примерно в одно и то же время. На протяжении всего исторического периода наблюдалась борьба между сторонниками нового образования, выступающими за сближение с передовой российской и западноевропейской наукой, и русским духовенством, проповедовавшим церковные догмы, и их противниками, отрицающими всякое развитие вообще. Достаточно долго нерешенными проблемами были отсутствие общепринятых программ для всех учебных заведений и согласованных сроков обучения. Принципиальные изменения в системе отечественного образования связаны с научной и педагогической деятельностью М.В. Ломоносова и его последователей. Подчеркивается важность появившейся в трудах педагогов в середине XIX века идеи о целесообразности учета возрастных и индивидуальных склонностей детей и разработке новой методики, построенной на активности и самостоятельности детей, которая позволила перейти к индуктивному пути обучения. Процесс изучение естествознания еще с XIX рассматривается как реальное и эффективное средство развития органов чувств, логического мышления и наблюдательности. Также дается объяснение необходимости сочетания индуктивного и дедуктивного метода обучения и обосновывается необходимость использования натуральных объектов, опытов и наблюдений в природе для развития учащихся.
\end{abstract}

